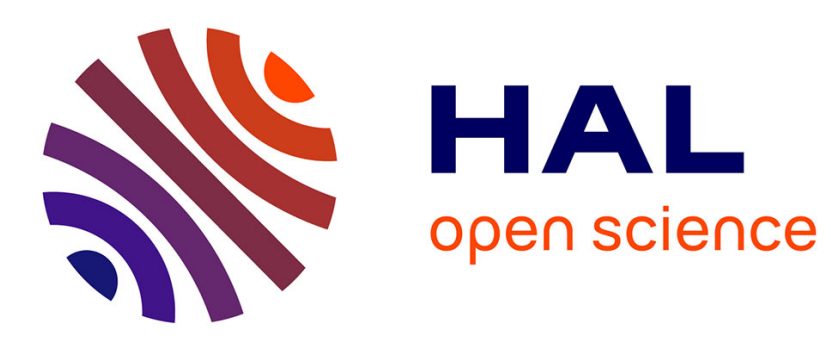

\title{
On experimental investigation of failure process of woven-fabric composites
}

\author{
M. Rokbi, H. Osmani, N. Benseddiq, A. Imad
}

\section{To cite this version:}

M. Rokbi, H. Osmani, N. Benseddiq, A. Imad. On experimental investigation of failure process of woven-fabric composites. Composites Science and Technology, 2011, 71 (11), pp.1375. 10.1016/j.compscitech.2011.05.003 . hal-00773219

\section{HAL Id: hal-00773219 \\ https://hal.science/hal-00773219}

Submitted on 12 Jan 2013

HAL is a multi-disciplinary open access archive for the deposit and dissemination of scientific research documents, whether they are published or not. The documents may come from teaching and research institutions in France or abroad, or from public or private research centers.
L'archive ouverte pluridisciplinaire HAL, est destinée au dépôt et à la diffusion de documents scientifiques de niveau recherche, publiés ou non, émanant des établissements d'enseignement et de recherche français ou étrangers, des laboratoires publics ou privés. 


\section{Accepted Manuscript}

On experimental investigation of failure process of woven-fabric composites

M. Rokbi, H. Osmani, N. Benseddiq, A. Imad

PII:

S0266-3538(11)00165-5

DOI:

10.1016/j.compscitech.2011.05.003

Reference:

CSTE 4983

To appear in:

Composites Science and Technology

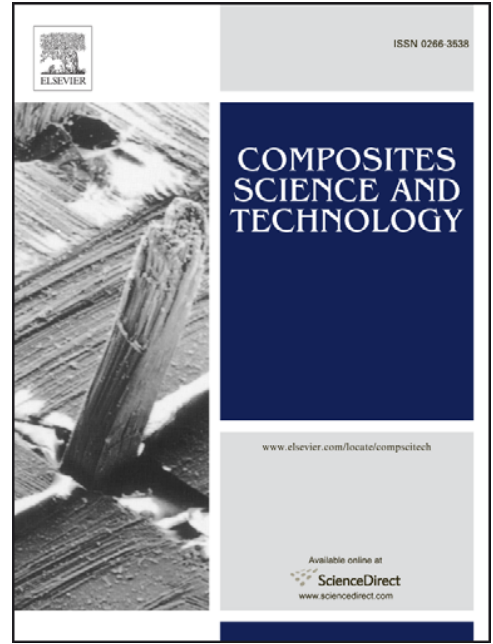

Received Date:

18 November 2010

Revised Date:

8 March 2011

Accepted Date:

8 May 2011

Please cite this article as: Rokbi, M., Osmani, H., Benseddiq, N., Imad, A., On experimental investigation of failure process of woven-fabric composites, Composites Science and Technology (2011), doi: 10.1016/j.compscitech. 2011.05.003

This is a PDF file of an unedited manuscript that has been accepted for publication. As a service to our customers we are providing this early version of the manuscript. The manuscript will undergo copyediting, typesetting, and review of the resulting proof before it is published in its final form. Please note that during the production process errors may be discovered which could affect the content, and all legal disclaimers that apply to the journal pertain. 


\title{
On experimental investigation of failure process of woven-fabric composites
}

\author{
M. Rokbi ${ }^{1}$, H. Osmani ${ }^{1}$, N. Benseddiq ${ }^{2,,}$, A. Imad $^{3}$ \\ 'Laboratoire de matériaux Non Métalliques, UFAS, OMP, Sétif 19000, Algérie. \\ ${ }^{2}$ University of Lille1, Laboratoire de Mécanique de Lille, IUT -A-, 2 rue de la recherche, 59653 \\ Villeneuve d'Ascq Cedex. \\ ${ }^{3}$ University of Lille1, Laboratoire de Mécanique de Lille, Cité Scientifique, Avenue Paul Langevin, \\ 59655 Villeneuve d'Ascq Cedex.
}

\begin{abstract}
In this paper an experimental investigation is performed to describe the fracture behaviour and failure mechanisms of woven fabrics composites, under static loading, using a compact tension test (CT). We studied the development of the different damage phases using the digital image correlation and the compliance method. The crack length was estimated at in the front of the notch tip. The approach of the effective crack length via the compliance procedure was compared to the measures of the damage in the epoxy/glass fiber composite obtained by the Digital Image Correlation (DIC).
\end{abstract}

Keywords: A. Polymer-matrix composites (PMCs); B. Fracture; C. Crack.

\section{Introduction}

The main benefits of Fiber Reinforced Polymer (FRP) are high stiffness, high strengthto- weight ratios, fatigue and corrosion resistance, low thermal conductivity, acoustical and

\footnotetext{
* * Corresponding authors. Tel.: +33 3266773 26; fax: +33 326677326 .

E-mail addresses: noureddine.benseddiq@univ-lille1.fr (Noureddine Benseddiq)
} 
thermal insulation. Generally, the fibers are the principal load-carrying members. The surrounding matrix keeps the fibers in the desired location and orientation. The matrix acts as a load transfer medium between the fibers and protects them from environmental damage. There are two major types of fabrics available in composites industry: woven and nonwoven fabrics [1]. Compared to unwoven unidirectional composites, the woven fabric composites provide good reinforcement in the warp and weft directions and lead to a reduction in the manufacturing costs of geometrically complex composites. However, the wider use of these materials in engineering applications is restricted by the lack of understanding of issues relating to their structural integrity, namely the difficulty of quantifying damage and predicting its evolution [2]. Various experimental methods are available to identify the localized damage induced by mechanical loading in notched composite laminates including optical (visual and photographic), ultrasonic, acoustic emission, electrical (eddy current and resistance) and compliance (displacement and back face strain gages) methods. Crack growth measurement is a crucial issue in mechanical engineering. Several techniques are used for crack extension detection. Among these, we have the ultra-sonic wave, acoustic emission and change in compliance of the specimen with crack growth. However, it seems that it is difficult to distinguish between cracking in the matrix and the fracture of fibers using the above techniques [3]. The development of optical measurement techniques have been developed over the past years. As a powerful technique in photo-mechanics, digital image correlation (DIC) has attracted more and more attentions from many researchers in recent years [4-6]. Perhaps this is due to its advantages including non-contact and real time measurement. The DIC is a computer vision technique that extracts the displacement data by comparing the features in a pair of digital images of a specimen surface before and after deformation [5-6]. The DIC method was used to obtain 
quite rapidly and easily crack growth and crack extension values with a good accuracy and a good spatial resolution.

The aim of this work is to describe the fracture behaviour and failure mechanisms of a composite epoxy/ woven fabric E-glass $2 \times 2$ twill by the DCI method. This technique is used and compared to measurement by compliance method.

\section{Experimental procedure}

\subsection{Materials and specimen}

The material used in this investigation is a composite of Epoxy M10 resin reinforced with $54.42 \%$ by volume of woven fabric E-glass $2 \times 2$ twill (Fig. 1). The weaving pattern used as reinforcement is the $2 \times 2$ twill weave. The superimposing of 28 layers of woven fabrics allowed having plates with $5.5 \mathrm{~mm}$ thickness. Tensile tests were carried out in this material for both the warp and weft yarns directions. The fibers characteristics were essentially identical in the warp and weft directions as shown in table 1 and 2 . The experimental curves of tensile tests are quite linear up to fracture. This corresponds to the behaviour of composites containing of a brittle matrix [7].

The fracture behaviour of composite was investigated using Compact Tension (CT) specimens, (Fig. 2). The specimens were cut from the prepared plates using a $2 \mathrm{~mm}$ thick diamond saw. This process was found to give a suitably smooth surface finish with a minimal sub-surface damage. The specimens were edge-notched with a diamond saw of $0.5 \mathrm{~mm}$ thickness. Cracks were propagated perpendicular to the warp or weft direction. This makes the study of effect of crack orientation on fracture process possible. Two different sets of compact tension are therefore produced. In the following, the CT specimens with the notch cut perpendicular to the warp direction are denoted "Mat-A" and those with the 
notch cut perpendicular to the weft direction are denoted "Mat-B". The notch tip of each specimen was carefully sharpened by means of a razor blade to initiate a natural pre-crack. Different crack lengths are produced to keep the $a / \mathrm{W}$ ratio in the range of $0.40-0.45$, with $\mathrm{W}$ equal to $50 \mathrm{~mm}$.

\subsection{Fracture toughness testing}

The tests were undergone on an Instron machine using a $10 \mathrm{KN}$ capacity servohydraulic testing machine. The monotonic loading during the tests was applied at constant displacement rate of $1 \mathrm{~mm} / \mathrm{min}$, and a minimum of seven specimens were tested for each composite.

The data reduction for Compact Tension (CT) or Compact Compression (CC) specimens made of an orthotropic material requires particular attention [8]. The laminate fracture toughness was calculated for each test using the stress intensity factor approach and the ASTM standard E399 [9]. This method was used previously by other researchers for the determination of the intra-laminar fracture toughness of composites using compact tension tests [8, 10-12]. According to ASTM standard E399, applicable for an isotropic material, the critical stress intensity factor for a fracture load $\mathrm{P}$, is given by the following analytical form [9]:

$K_{I C}=\frac{P}{B \cdot \sqrt{W}} Y(\alpha)$

Where $\mathrm{B}$ is the thickness of the specimen, $\alpha$ is the relative notch depth $(=a / W)$ and $Y(\alpha)$, given by Equation (2), is the well-known polynomial function formulated by Srawley [13]: 


$$
Y(\alpha)=\frac{(2+\alpha)}{(1-\alpha)^{3 / 2}} \cdot\left(0.886+4.64 . \alpha-13.32 \cdot \alpha^{2}+14.72 . \alpha^{3}-5.6 . \alpha^{4}\right.
$$

For a uniaxial or plane-stress in an orthotropic plate with a crack subjected to the opening mode, Griffith's strain energy release rate, $G_{R}$, is related to critical stress intensity factor as follows [14-16]:

$$
G_{R}=\frac{\mathrm{K}_{\mathrm{R}}^{2}}{\sqrt{2 \cdot E_{x} \cdot E_{y}}} \cdot \sqrt{\sqrt{\frac{\mathrm{E}_{\mathrm{x}}}{\mathrm{E}_{\mathrm{y}}}}+\frac{E_{x}}{2 \cdot G_{x y}}-v_{x y}}
$$

Where $E_{x}, E_{y}, v_{x y}$ and $G_{y x}$ are the effective elastic characteristics of the composite.

\subsection{Measurement of crack growth}

In the present study, the digital image camera (DIC) technique was monitored in situ during the fracture process. The goals of adopting the DIC method are (i) to distinguish the different failure sequences by direct observation, (ii) to detect the crack initiation and follow its growth along the CT specimen and (iii) to evaluate the crack increase at different times (t). To ensure a good and clearer observation, the samples surface were polished using different nuances of glass-paper $\left(180,320,500\right.$ grains $\left./ \mathrm{cm}^{2}\right)$. The specimen was illuminated using normal fluorescent lamp that allowed a very uniform level of illumination throughout the surface. The camera was placed perpendicularly to the specimen surface at a distance of $1.2 \mathrm{~m}$. Images (700x575 Pixels) were captured by a LAVISON IMAGER PRO Charge Couple Devise (CCD) video camera with 2 frames per second capture rate using $\times 40$ magnification lens. For this camera alignment, the pixels in the image represent an approximately $270 \mu \mathrm{m}$ square on the specimen surface. The resolution for the test set-up was 3.7 pixels $/ \mathrm{mm}$. The focus distance is adjusted by using a 
micrometer translator. Before starting the fracture test, the dimensional characteristics of the CT specimen are introduced into the software. In our case, the unbroken length (ligament) is (W-a). It is important to note that the system Image Pro Lavison, adopted in this study, is designed for the treatment of $2 \mathrm{D}$ problems where the vertical and/or the horizontal deformation (crack propagation) are easily obtained. As the fracture paths in both directions are predominantly linear, the position of a crack tip at any given time $\left(\mathrm{t}_{\mathrm{q}}\right)$ is followed by its projection on the center line (line 1 in figure 3 ). The crack length $a_{t q}$ at any time $t_{\mathrm{q}}$ is then recorded and can determined by means of the software (Devis) used for analysing the recorded images. For every image taken by the DIC technique at any time during the test, a load and a displacement are associated. Fig. 4 shows a selected sequence of CCD images depicting crack growth in the CT specimen. The time $\mathrm{t}=0 \mathrm{~s}$ corresponds to the beginning of loading.

The test set up with the equipment used to capture images is shown in figure 5. The Initiation of crack growth was defined when the whitened zone could be clearly discerned around the main crack front. A set of 180 images were obtained from each fracture test. The crack growth measurement was made by image analysis. It consists basically in comparing the distance between the marks on the specimen surface corresponding to the visible crack length using the commercially available software (Devis).

On the other hand, the in-plane displacement is also determined using the compliance method in order to see the correspondence of the measures of the damages in the epoxy/glass fiber composite determined by the DIC method.

The compliance method is an effective way of determining the fracture characteristics of brittle materials. Compliance can be calculated from a load-displacement curve $(\mathrm{P}-\delta)$ 
$[17,18]$, or from a load-crack opening displacement curve (P-COD) $[19,20]$. In the present study, we used the load-displacement curve.

The increase of the specimen compliance due to the fracture process zone development is attributed to the propagation of an effective crack or in other terms, an equivalent elastic crack of length aeq. The effective crack increment for two successive loading-unloading cycles can be calculated using the iterative relation of Tada [21]:

$$
a_{n+1}-a_{n}=\frac{W-a_{n}}{2} \cdot \frac{C_{n+1}-C_{n}}{C_{n+1}}
$$

Where $\mathrm{C}_{\mathrm{n}}$ and an are respectively the compliance and associated crack length values and $\mathrm{W}$ is the width of the specimen.

\section{Results and Discussions}

The Compact Tension (CT) experiments were monitored through the recording of the associated load-displacement curve $(\mathrm{P}-\delta)$, where the displacement was measured between the two loading pins. Typical load versus displacement curve of each set of CT specimen is shown in Fig. 6. For both samples, the Mat-A and Mat-B, the (P- $\delta$ ) curves evolution are similar. First, the $(\mathrm{P}-\delta)$ curves are initially linear than deviate progressively from linearity as the slow crack growth or damage occurs in the region of the notch tip front. Taking into account the local inhomogeneous material property, we may conclude that the reproducibility of experiments is acceptable for each batch.

In order to study the change in the failure behaviour in more details, the evolution of the load versus displacement is analysed from the events given by the CID technique. Figure 7 shows the "Mat- $A$ " composite load-displacement $(\mathrm{P}-\delta)$ curve. Various loading levels during the CT specimen fracture tests are compared to the microscopically observed 
failure events at the crack-tip (Fig. 8). We can say that four failure stages characterize the load-displacement curve.

Stage I: It corresponds to the elastic linear phase (OA) where no damage appears yet in the specimen (Fig. 8). Only linear elastic deformation occurred in the matrix and no micro-cracks were formed [22-24]. For two different sets of compact tension, the load deflection curves have an initially linear response.

Stage II: In this stage (AB), there is a progressive nonlinearity in the curve $(P-\delta)$. It also appears a crack-tip blunting. This characterizes the initiation of matrix microcracking (Fig. 8a). The fracture and damage regions of the composite in the notch tip zone are clearly distinguished as white damaged areas [22-24]. The blunting zone is whitish. Some micro-cracks are formed and increase very slowly. The DIC method allows us to determine the loading level corresponding to the initiation of the crack (point $\mathrm{B}: \mathrm{P}_{\mathrm{B}}=4722 \mathrm{~N}, \mathrm{t}=1 \mathrm{mn} 42 \mathrm{~s}$ ) in composite Mat- $A$. It was about $92 \%$ of the maximum load Pmax. It was noticed that at this loading level, no fiber damage was detected.

Stage III: In this phase (BC), transverse cracking occurs along different layers and some longitudinal cracking along the composite layers near the crack tip appear. The fracture of the composite at the notch root begins from a matrix cracking near the maximum load. Audible noise associated with visibly stressed area, due to the high transparency of the matrix, was observed [25]. The increase in load causes initiation of the crack in the composite. The first matrix cracking occurs in a pop-in like manner. One fiber bundle unit fracture follows this pop-in like matrix cracking [26]. 
Therefore it is possible to predict that the fiber breakages do not occur until reaching the maximum loading (point $\mathrm{C}: \mathrm{P}_{\mathrm{C}}=5135 \mathrm{~N}, \mathrm{t}=2 \mathrm{mn} 10 \mathrm{~s}$ ). During the first 10 seconds of this stage, the crack grew only to $0.26 \mathrm{~mm}$. The crack progression remains slow and progresses in a stable manner until $3.5 \mathrm{~mm}$. The fibers tend to bridge and stop existing cracks, causing a loading distribution in the material (Fig. 8b,c). This load redistribution is spread throughout the specimen until it reaches a maximum loading. Beyond this point, the additional energy must be absorbed by the largest crack growth. The noises may be due to subcritical microcrack damages caused by fibers fracture, delaminating, and matrix cracking at the notch tip [25]. Khanna and Shukla [26] detailed the crack fiber interaction as fellow: When a crack front hits a fiber, the principal crack front moves on both directions along the fiber. It evolves slowly around the fiber producing a debonding zone all around. With an increase in the load, this leads to the fibre fracture at the weakest zone.

Stage IV: After the maximum load point, the main crack continued to propagate as shown in Fig. 8d,e,f,g, $\boldsymbol{h}$, and leading to a load decrease. In this stage, the crack growth is more important than in stage III. During the first 10 seconds of this phase, the crack grew up to $2.93 \mathrm{~mm}$, and continues its growth in an unstable manner. This produced a gradual failure $[\mathbf{2 1 , 2 3}$. Several mechanisms, like matrix microcracking, fiber debonding and fiber breakage, seem involve in the crack growth. The formation of new surfaces (white area in Fig. 8e ) tends to weaken the matrix. The formation of new surfaces (white area in Fig. 8e ) tends to weaken the matrix. Consequently, the pull-out is reduced and the rupture is dominated by shear stresses. It is noticed that the micro-cracking damage zone spreads continuously. 
The tests carried out on the two composite groups show that both are characterized by the same crack growth process stages. Critical load levels that are determined from a combination of values obtained by testing fracture (curve $(\mathrm{P}-\delta)$ ) and photographs produced by CID technique, are fairly similar (Table 3). This indicates that the tensile strength of materials Mat-A and Mat-B are almost identical. Moreover, the critical recorded load levels remain somewhat close for both the tested composites.

According to table 3, it appears that the Mat-A (crack perpendicular to the warp) initiated at a load value a little bit higher compared to Mat-B (crack perpendicular to the weft). This difference is around $6 \%$. However, the failure of both composites occurs at a very close load level. Fig. 9 shows the load versus crack growth response for two tested materials. After crack-tip blunting and micro-cracking growth, the first fiber fracture effect is observed once the maximum load is reached. At this level, an increase of crack $\left(\Delta \mathrm{a}_{\text {rup }}\right)$ is detected in each notch direction. It corresponds to about $0.58 \mathrm{~mm}$ for both notch directions. Beyond the maximum load, the main crack continued to grow as the load decreases.

\subsection{Sequences of crack extension in composite reinforced woven fabric}

The study of static fracture of both notch directions shows that the crack spreads in a similar manner (Fig. 10). Once again, this figure shows that the effect of notch direction does not have a large effect on the tensile strength of such material, although a slight shift

in favor of Mat-A is observed. Three phases of evolution of the crack are observed during the crack progress in CT specimens (see Fig. 11).

Phase I: This phase marks the initiation of the crack growth. After blunting and microcrack growth near the crack-tip, the main crack is clearly observed. It spreads more easily around the bundle. As the load increases, the bundle section weakens until it breaks near maximum loading. After this point, the load decreased gradually and 
instable crack growth was observed. The DIC technique shows that the local damage zone recorded during this phase is about $3.5 \mathrm{~mm}$. This phase is characterized by a stable crack growth and corresponding to the portion (BC') in

\section{Fig. 7.}

Phase II: An important damage zone (19mm) was observed during this phase (Fig. 11). Compared with the first phase, the second is characterized by more extensive damage areas (portion $\mathbf{C}^{\prime} \mathbf{C}^{\prime}$ ' in Fig.7). Moreover, the leap of rupture, which represents the advance of the tip of the crack, is more important. In all tested specimens, the fracture paths in both directions are predominantly linear. A spread of white area is observed along the damage process (see Fig. 12). This means that the damage zone evolution is accompanied by significant bundle bridging. Liu and Hughes [23] indicated that the degree of stress whitening appeared to be dependent upon the type of crack growth behaviour. Several mechanisms can be manifested during the crack growth process. These mechanisms sum up in micro-cracking in matrix, fiber/matrix debonding and fiber pull-out. In addition, longitudinal bundle unit fiber pull out are observed along the damage zone as shown in Fig. 13. On the other hand, the photographs in Fig. 13a and 13b showed that the longitudinal fibers bundle unit pull outs are more important in Mat-B than Mat-A. It's seemed that the weft bundles were well impregnated than the warp bundles. This finding reveals no significant difference in the initial cracking toughness parameters $\left(\mathrm{G}_{\mathrm{I}-\mathrm{Ini}}\right.$ and $\left.\mathrm{K}_{\mathrm{I}-\mathrm{Ini}}\right)$, but there is an increase on the plateau toughness parameters. This increase is about 10 and $4 \%$, respectively, for $\mathrm{G}_{\mathrm{R}-\mathrm{Prop}}$ and $\mathrm{K}_{\mathrm{R}-\mathrm{Prop}}$,

Phase III: This phase corresponds to the portion (C''D) in Fig. 7. The CID technique shows that this phase is the shortest and slowest step of the rupture. The velocity of the fracture process is slowing down more and more. It should be noted that the 
parameters recorded during this phase may not be reliable for the tested material since the crack is strongly influenced by the side effect. The crack tip propagated in this phase in an unstable manner.

We correlated the R-curves data with those presented in Figs. 7 and 11. The transition between the R-curves and figure 7 is achieved using the results obtained in Fig.11 by adding a third axe $(\mathrm{t})$ in Fig.7 $(\mathrm{P}=\mathrm{f}(\delta, \mathrm{t}))$.

\subsection{Comparison of methods of crack length estimation}

The in-plane crack displacement assessment is a crucial issue in fracture toughness. For this reason, choosing a method of measuring of crack propagation must be carefully studied. During this study, two methods were used to see which of the two is more accurate.

- The digital image correlation (DIC) technique,

- $\quad$ The compliance method.

In order to compare the two methods, these were adopted simultaneously during the study of the composite breakage. Figures 14 and 15 illustrate the superposition of the evolution of the load accordance with the increase of crack length respectively for material Mat-A and Mat-B. From the first survey of these two figures, it appears that for any load level, the two methods of measurement indicated that the crack growth increments are very close. The maximum recorded on these curves (Fig. 14 and 15) does not exceed 3\%. The loadcrack length curve obtained using the compliance method is smooth. The crack length obtained using the DIC method is unstable once the crack had initiated, resulting in a steplike appearance in the load-crack length curve. By using the DIC method, the crack propagation was always observed to start along the fibers in the inner layers of the 
specimen rather than at the surface [5]. The optical initial and final crack sizes were assumed as being the physical initial and final crack sizes [27]. It was noted that the physical crack growth or process zone extended beyond the apparent crack face. Thus, the crack length determined by the DIC is longer than the effective crack length determined by the compliance method.

\subsection{Calculation of composite fracture toughness}

As shown above, two methods are adopted to determine the crack growth in different composites. Thus, we presented a comparison between them. In what follows, the crack lengths determined by the two methods are adopted to show the distinctions that can be presented in the evaluation of fracture toughness.

Values for $G_{R}$ and $K_{R}$ were plotted as a function of crack length to produce a resistance R-curves which were estimated from the experimental data using equations (1,2 and 3). From the present experimental results, the R-curves of the two composites initiate at different toughness values (see Figs. 16, 17, 18 and 19). In each R-curve, two stages are observed; the first stage is an increase in the toughness values with stable crack growth.

The second one is propagation according to a plateau value; this level is characterized by crack instability. There are no distinguishing features between the stable and the unstable crack growth regions [3]. The rising R-curves indicate that some type of energy absorption is occurring during the fracture process [28].

Table 4 and 5 summarize the average mode-I fracture toughness and the energy release rate values, respectively, for both orientations using compliance and DIC methods. The intrinsic toughness $\mathrm{K}_{\mathrm{I}-\mathrm{init}}$ and $\mathrm{G}_{\mathrm{I}-\mathrm{nit}}$ are the first values in the curves and correspond to the onset of crack growth in each composite. For both methods, these values are very close. By comparing the crack lengths determined by DIC Method (Fig. 16), and those determined by 
compliance method (Fig.17), it is apparent that the composite with the notch cut perpendicular to the warp direction, (Mat-A) suffers the first effect of cracking (see table 4 and 5). Once the micro-crack is initiated (point B in Fig.7), the toughness, based on the micro-crack, rapidly increased according to a stable crack growth (portion (BC') in Fig.7 or phase I in Fig.11). For R-curves obtained using DIC method (Fig. 16), unstable fracture toughness is observed. This is represented by phase II in Fig.11 or portion (C'C') in Fig. 7. However, the R-curves, obtained using the compliance method, are smooth (see Fig. 17). In this figure the plateau region is clearly observed. In all test results, the R-curves show a decreasing trend when the extending crack tip approaches the back surface of the CT specimen (phase III in Fig.11 or portion (C'’D) in Fig. 7), this is probably due to the specimen end effect [29].

A clear distinction between the evolutions of the R-curves of the studied composites is observed in Fig. 16 and 17. The composite Mat-A exhibits a higher plateau value, $\mathrm{K}_{\mathrm{I}-\mathrm{prop}}$, compared to the composite Mat-B (Table 4 and 5). That can be allotted to the following reasons: (i) higher fibre bundle spacings in the warp direction than in the weft direction, lower fibre spacing yielding more secondary matrix cracking [30], and (ii) higher number of crimps and higher crimp angle in the weft direction. The fibre crimps produce local stress perturbations under uniaxial tension, which cause large normal and shear strains to concentrate [31]). Jortner [30], has introduced the idea of characterizing fibre bundle curvature by measuring the crimp angle $\theta$. He demonstrated that the lower average crimp angle was responsible for the higher modulus. This same reason also caused the higher tensile strength $[\mathbf{2 8 , 3 0}]$.

\section{Conclusions}

In this study, an experimental investigation is performed to describe the fracture behaviour and failure mechanisms of a composite epoxy/ woven fabric E-glass 2x2 twill. 
The experimental results indicate that the composite fracture behaviour and failure mechanisms remain nearly unchanged when the cracks were propagated perpendicular to warp or weft direction.

The digital image correlation is an effective tool for the detection of various stages of the composite damage. These stages correspond to the crack-tip blunting, the crack initiation and the beginning of various damage mechanisms (fiber-matrix debonding, fiber pull out, delamination and fracture of matrix or glass fiber).

Even though a difference was observed between the physical cracks lengths measured using DIC technique and the effective one measured using compliance method, the experimental results show a good agreement in the crack length evolution by both techniques. In perspective, we are aiming to perform the DIC technique simultaneously on both surfaces of the compact tension specimen in order to better appreciate the crack length and to detect the eventual dissymmetry.

\section{Acknowledgements}

The authors gratefully acknowledge Mr Salim Benmedakhene, President Director General of AE Tech, for providing us with composite materials.

\section{References}

[1] Abdussalam SR, Ayari ML. Experimental study of fracture toughness and energy in composite materials. Mech Compos Mater 1998; 34(3):235-42.

[2] Kyriazoglou C, Le Page BH, Guild FJ. Vibration damping for crack detection in composite laminates. Compos Part A 2004; 35(7-8):945-53.

[3] Yanada H, Homma H. Study of fracture toughness evaluation of FRP. J Mater Sci 1983; 18(1):133-39.

[4] Li M, Zhang J, Xiong CY, Fang J, Li JM, Hao Y. Damage and fracture prediction of plastic-bonded explosive by digital image correlation processing. Opt Laser Eng 2005; 43(8):856-68.

[5] Gonzăles L, Knauss WG. Scaling global fracture behavior of structures-sized laminated composites. Int J Fracture 2002; 118(4):363-94. 
[6] B. Mouhmid, A. Imad, N. Benseddiq, D. Lecompte. An experimental analysis of fracture mechanisms of short glass fibre reinforced polyamide 6,6 (SGFR-PA66), Compos Sci Technol 2009, 69(15-16):2521-26

[7] Benmedekhene S. Etude Phénoménologique du Comportement à l'Impact des Matériaux Composites. Thèse de doctorat UTC, Université de Compiègne,1996, Chapitre 2.

[8] Pinho ST, Robinson P, Iannucci L. Fracture toughness of the tensile and compressive fibre failure modes in laminated composites. Compos Sci Technol 2006; 66(13): 206979.

[9] ASTM. Standard test method for plane-strain fracture toughness of metallic materials. ASTM standard E399-90; 1993

[10] Jose S, Ramesh Kumar R, Jana MK, Venkateswara Rao G. Intralaminar fracture toughness of a cross-ply laminate and its constituent sub-laminates. Compos Sci Technol 2001;61(8):1115-22.

[11] Li X, Hallett SR, Wisnom MR, Zobeiry N, Vaziri R, Poursartip A. Experimental study of damage propagation in Over-height Compact Tension tests. Composites: Part A 2009 ; 40(12): 1891- 99.

[12] Cowley KD, Beaumont PWR. The interlaminar and intralaminar fracture toughness of carbon-fibre/polymer composites: the effect of temperature. Compos Sci Technol 1997;57(11):1433-44.

[13] Srawley JE. Wide range stress intensity factor expressions of ASTM E 399 Standard fracture toughness specimens, Int J Fracture 1976; Vol. 12(3):475-76.

[14] Irwin, GR. Analytical aspects of crack stress field problems. TAM Report no. 213, University of Illinois, Urbana, IL, 196.

[15] Sih, GC, and Liebowitz, H. Mathematical theories of brittle fracture. In Fracture, ed. H. Liebowitz. Academic Press, New York 1969, 67-190.

[16] Lin ST, Feng Z, and Rowlands RE. Thermoelastique determination of stress intensity factors in orthotropic composites using the J-integral. Eng Fract Mech 1997; 36(4) :579-92

[17] Meille S, Saâdaoui M, Reynaud P, Fantozzi G. Mechanisms of crack propagation in dry plaster. J Eur Ceram Soc 2003; 23(16): 3105-12

[18] Morel S, Dourado N, Valentin G, Morais J. Wood: a quasibrittle material R-curve behavior and peak load evaluation. Int J Fracture 2005; 131(4):385-400

[19] Kostopoulos V, Markopoulos YP. On the fracture toughness of ceramic matrix composites. Mater Sci Eng A 1998; 250(2):303-12

[20] Kostopoulos V, Markopoulos YP, Pappas YZ, Peteve SD. Fracture Energy Measurements of 2-D Carbon/Carbon Composites. J Eur Ceram Soc 1998; 18(1):6919.

[21] Tada H, Paris P, Irwin G. The Stress Analysis of Cracks Handbook. Del Research Corporation, 1973.

[22] Xu S, Gao S. Fracture and Tensile Properties of Polyvinyl Alcohol Fiber Reinforced Cementitous Composites. J Wuhan University Technol-Mater Sci Ed 2008; 23(1):7-11. 
[23] Liu Q, Hughes M. The fracture behaviour and toughness of woven fax fiber reinforced epoxy composites. Compos Part A 2008; 39(10):1644-52.

[24] Kawazoe S, Kagawa Y. Application of photon emission technique to the determination of micro-fracture behavior in glass fiber-reinforced epoxy matrix composite. Sci Technol Adv Mat 2001; 2(2):425-31.

[25] Khashaba UA. Behavior of Woven Composites Containing Various Cracks Geometry. J Compos Mater 2003; 37(1):5-20.

[26] Khanna SK, Shukla A. Absorption mechanisms during dynamic fracturing of fibrereinforced composites. J Mater Sci 1993; 28(14): 3722-30.

[27] Castrodeza EM , Schneider Abdala MRW, Bastian FL. Crack resistance curves of GLARE laminates by elastic compliance. Eng. Fract Mech 2006; 73(16):2292-2303

[28] Grieshheim GE, Pollock PB, Yen SC. Notch Strength and fracture behavior of 2-D Carbone-Carbone Composites, J Am ceram Soc 1993; 76(4):944-56.

[29] Sato K, Hashida T. Fracture toughness evaluation based on tension-softening model and its application to hydraulic fracturing. Pure Appl. Geophys 2006; 163(5-6):107389.

[30] Jortner J. Effects of Crimp Angle on the Tensile Strength of a Carbon-Carbon Laminate, Proc. Symposium on High Temperature Composites, Lancaster, 1989, 243 51 .

[31] Kim JK, Sham ML, Impact and delamination failure of woven-fabric composites, Compos Sci Technol 2000; 60(5), 745-61, 


\title{
On experimental investigation of failure process of woven-fabric composites
}

\author{
M. Rokbi, H. Osmani, N. Benseddiq, A. Imad
}

\begin{tabular}{cccc}
\cline { 2 - 4 } & $\begin{array}{c}\text { Tensile modulus at } 25^{\circ} \mathrm{C} \\
(\mathrm{GPa})\end{array}$ & Poison's ratio & $\begin{array}{c}\text { Failure stress } \\
(\mathrm{MPa})\end{array}$ \\
\hline Warp & 27.4 & 0.14 & 417.4 \\
\hline Weft & 28.2 & 0.14 & 441.5 \\
\hline
\end{tabular}

Table 1: Mechanical properties of the twill fabric glass 2x2 [7]

\begin{tabular}{lccccc}
\cline { 2 - 4 } & $\begin{array}{c}\mathrm{E}_{\mathrm{x}}=\mathrm{E}_{\mathrm{y}} \\
(\mathrm{GPa})\end{array}$ & $\begin{array}{c}\mathrm{E}_{\mathrm{z}} \\
(\mathrm{GPa})\end{array}$ & $\begin{array}{c}\mathrm{G}_{\mathrm{xy}} \\
(\mathrm{GPa})\end{array}$ & $\begin{array}{c}\mathrm{G}_{\mathrm{xz}}=\mathrm{G}_{\mathrm{yz}} \\
(\mathrm{GPa})\end{array}$ & $\begin{array}{c}v_{\mathrm{xy}} \\
(\mathrm{GPa})\end{array}$ \\
\hline Experimental & 27.4 & $\ldots \ldots$ & 5.20 & $\ldots \ldots$ & 0.14 \\
\hline Analytical & 25.9 & $\ldots \ldots$ & 6.10 & $\ldots \ldots$ & 0.13 \\
\hline Numeric & 26.2 & 11.6 & 5.80 & 3.38 & 0.15 \\
\hline
\end{tabular}

Table 2: Comparison between the experimental, analytical and numeric results obtained for the twill fabric glass/epoxy 2x2 [7]

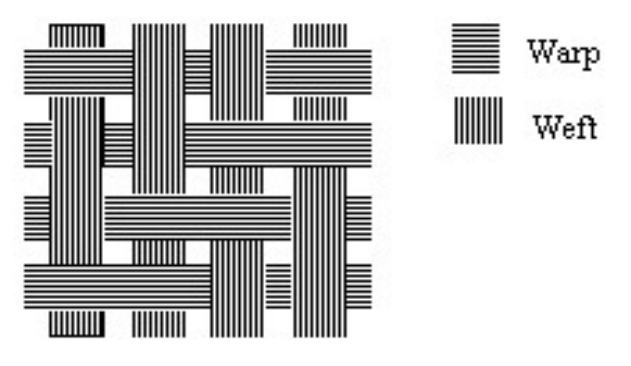

Fig. 1. 2D image of unit cell of the twill weave $2 \times 2$ 


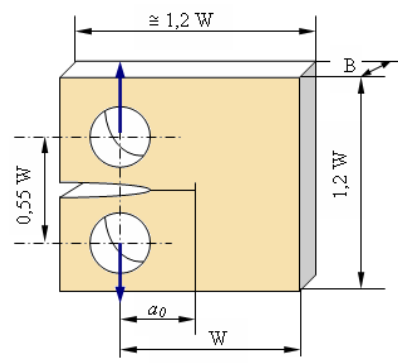

Fig. 2. Geometry of CT specimen

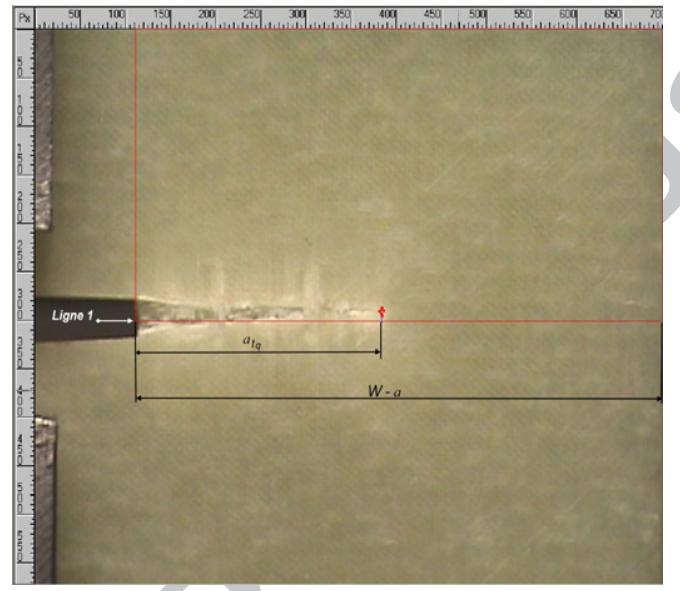

Fig. 3. The determining of the increase of crack length in CT specimen by the DIC method
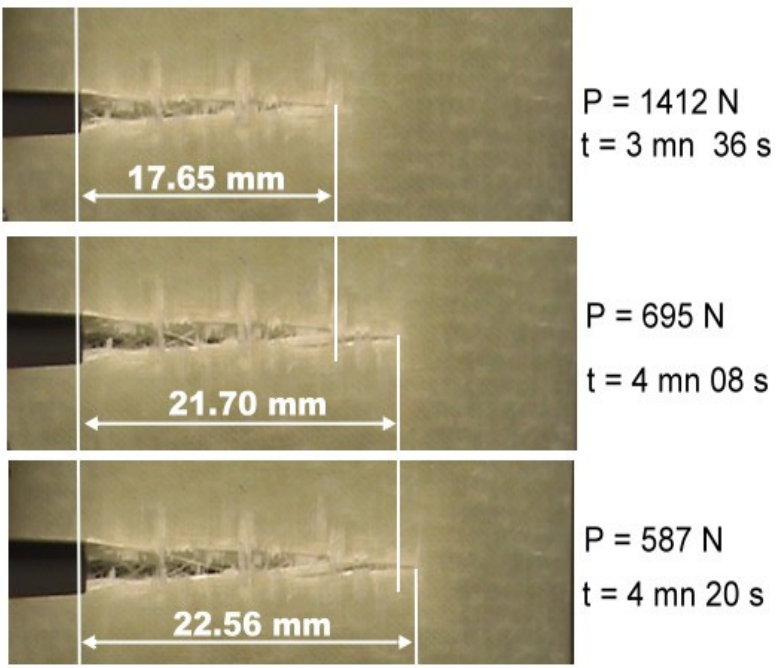

Fig. 4. A sequence of CCD images illustrating crack growth in Mat-A. 


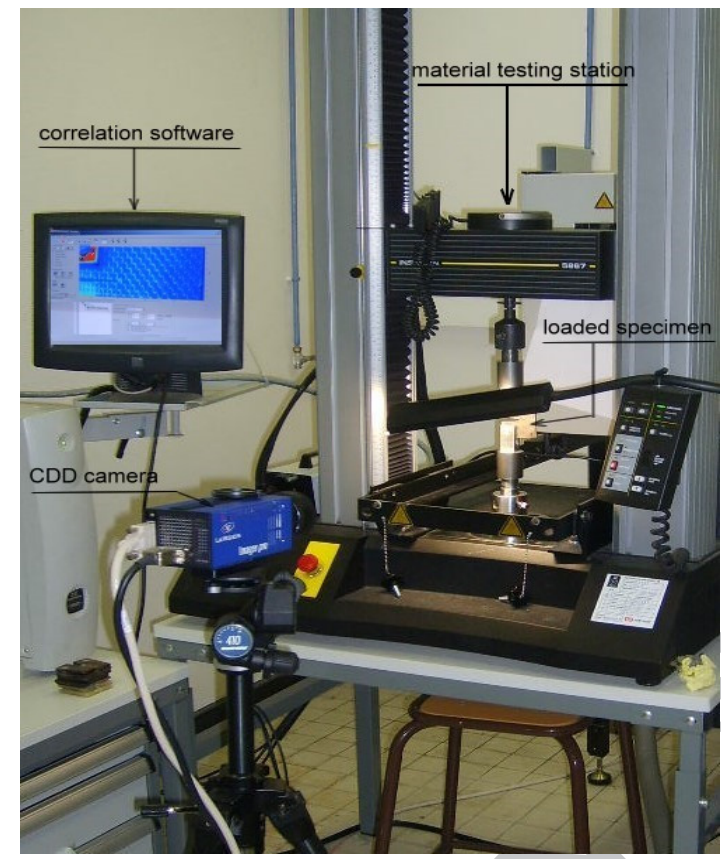

Fig. 5. Experimental set-up and images capture of the CT specimens.
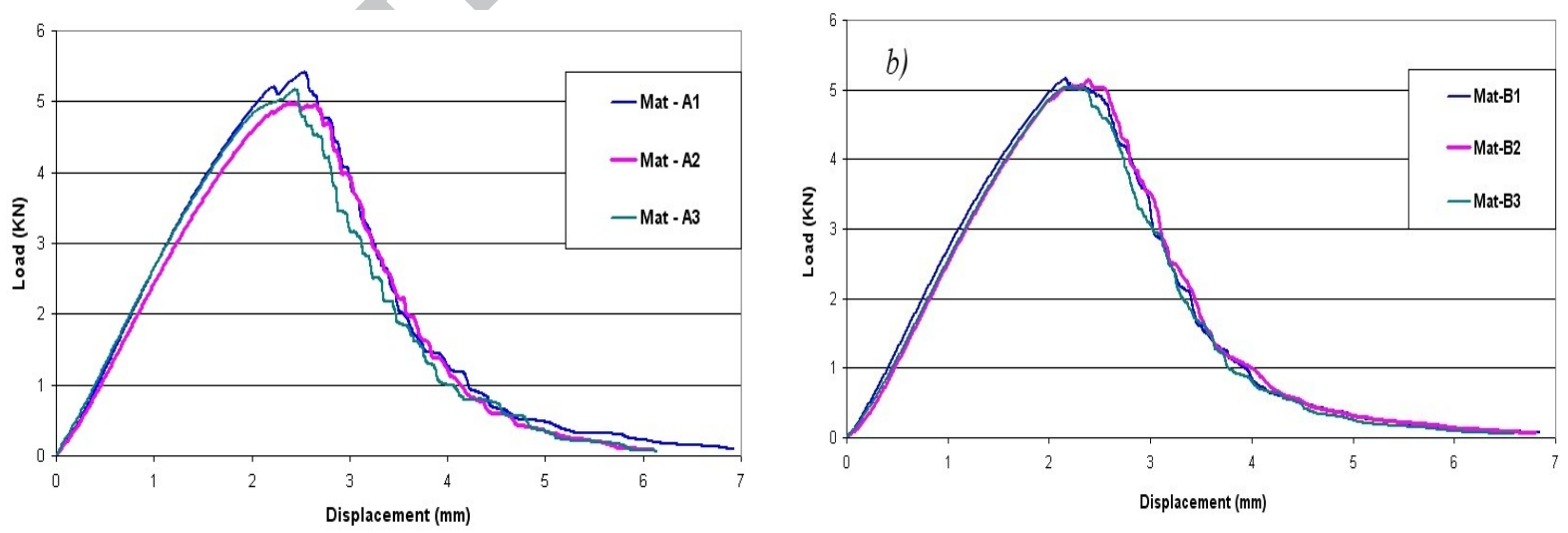

Fig. 6. Load versus displacement of a) Mat $-A$ and $b)$ Mat $-B$. 


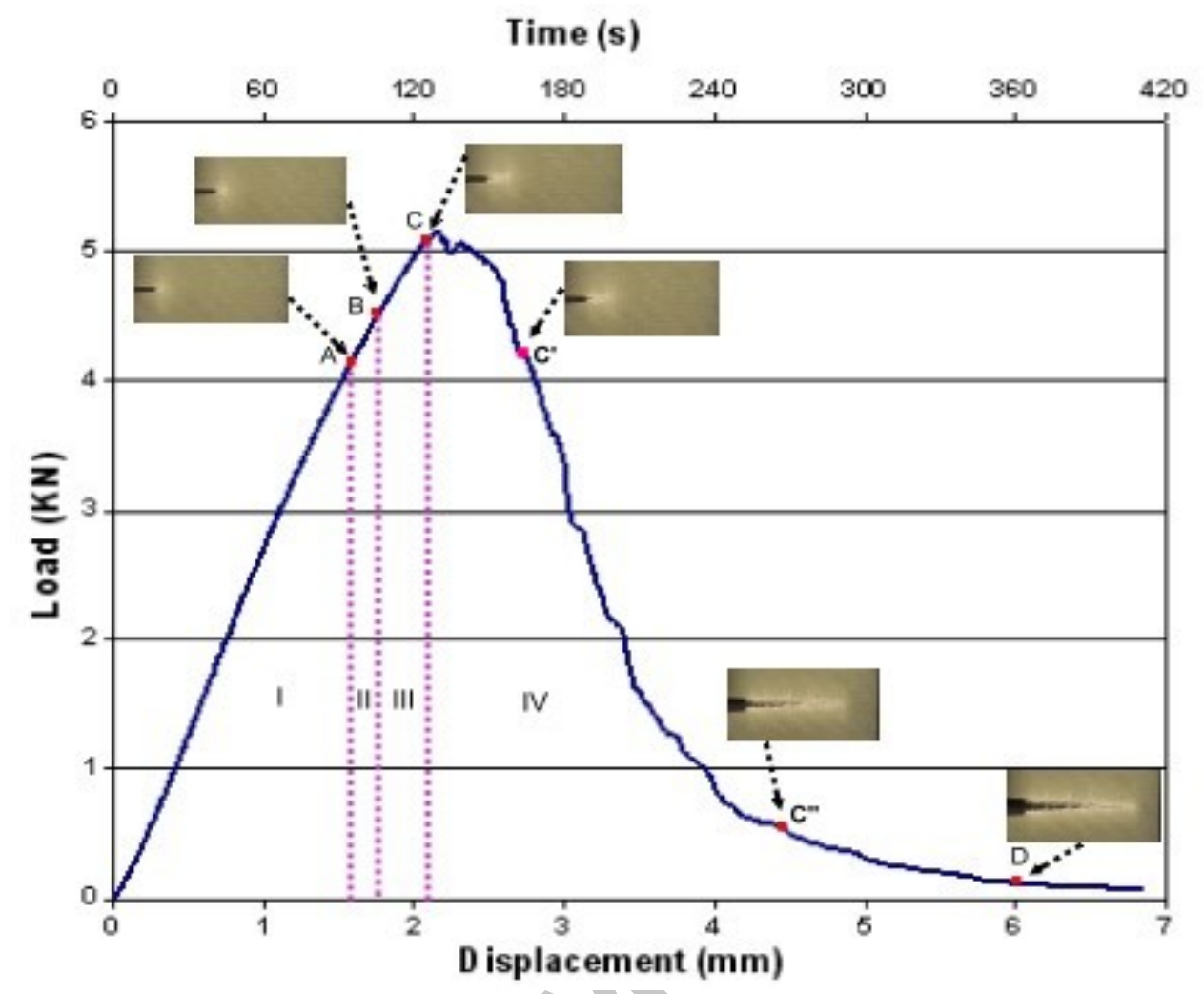

Fig. 7. Distribution of the sequences characterizing the fracture process of tested composite (Mat-A) 

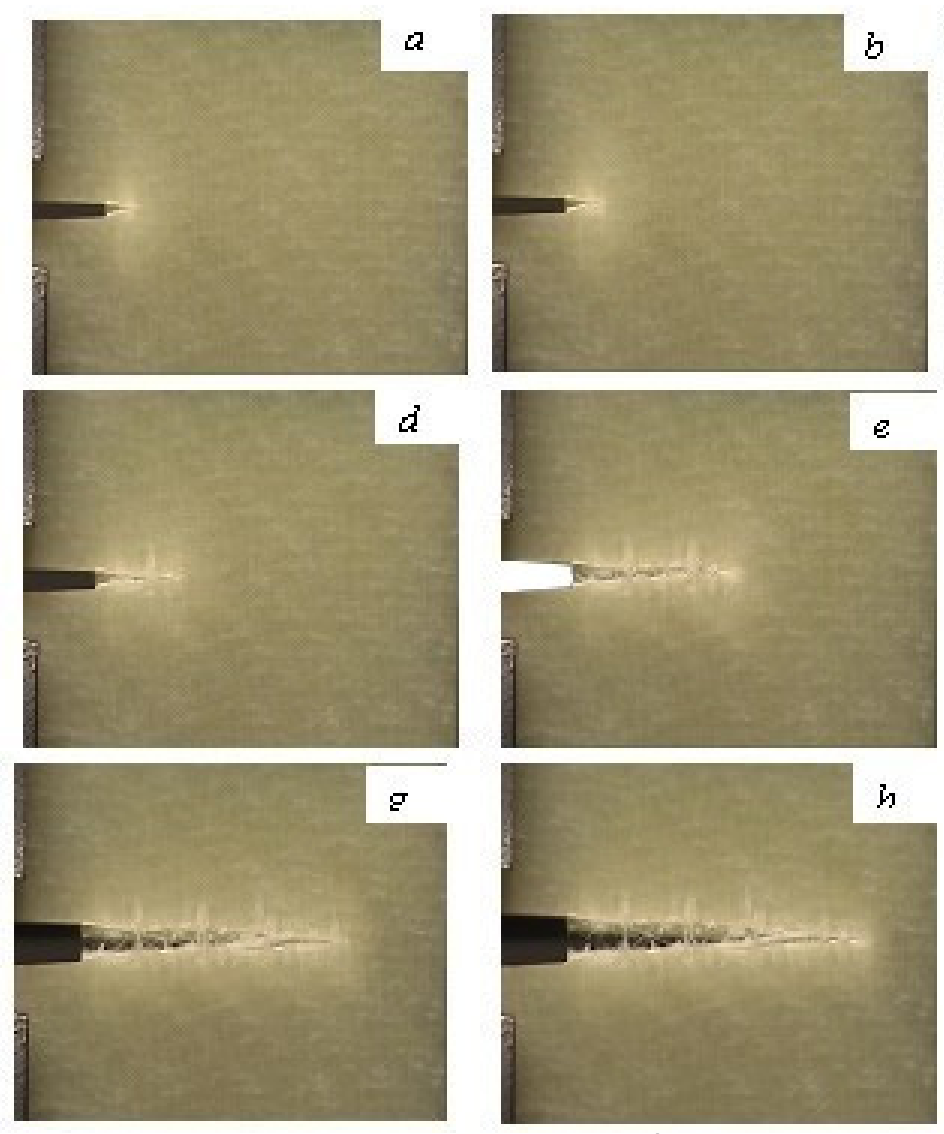

c

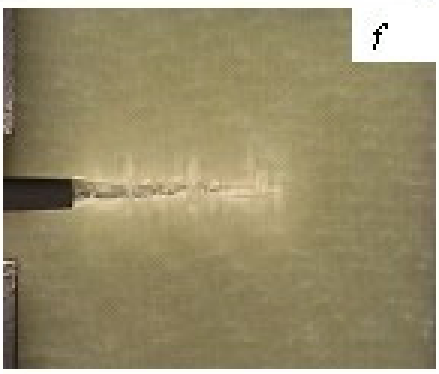

$f$

Fig. 8- Crack growth images of tip during fracture experience

\section{Table 3}

Remarkable levels of loads of the various studied composites

\begin{tabular}{|c|c|c|c|}
\hline & & Load (KN) & \\
\hline Appellation & blunting & In first cracking & Maximum \\
\hline$M a t-A$ & 4.2792 & 4.9168 & 5.1646 \\
\hline Mat - B & 4.0378 & 4.8473 & 5.1470 \\
\hline
\end{tabular}




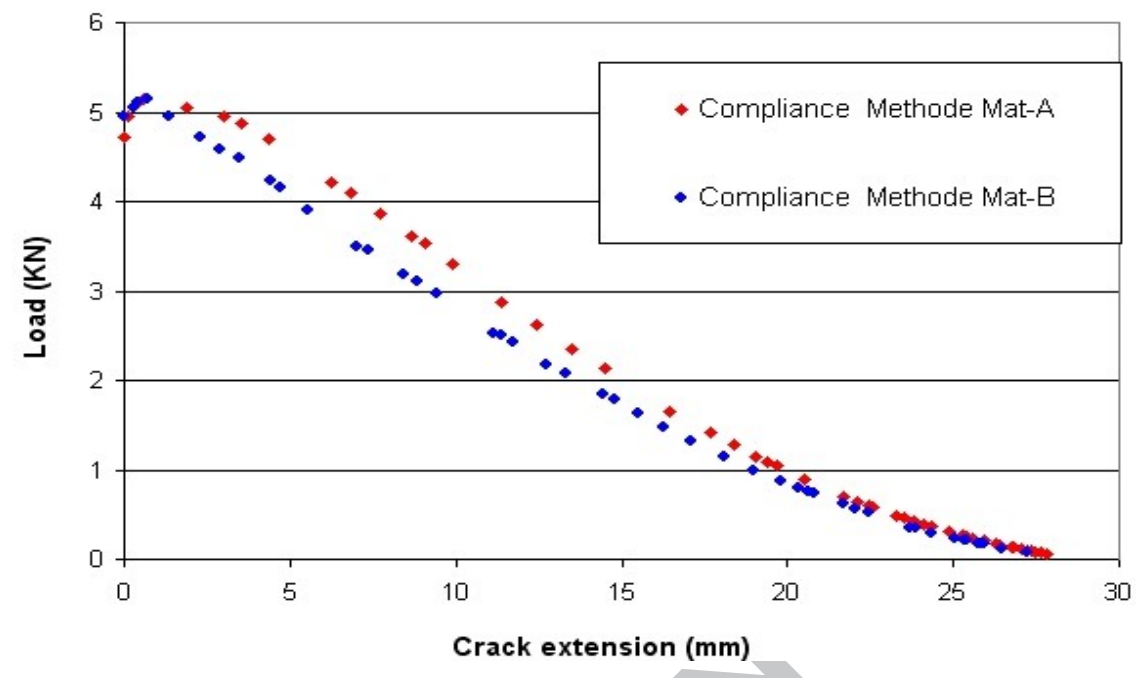

Fig. 9. Comparison of evolution of crack in two notch directions using load vs crack extension

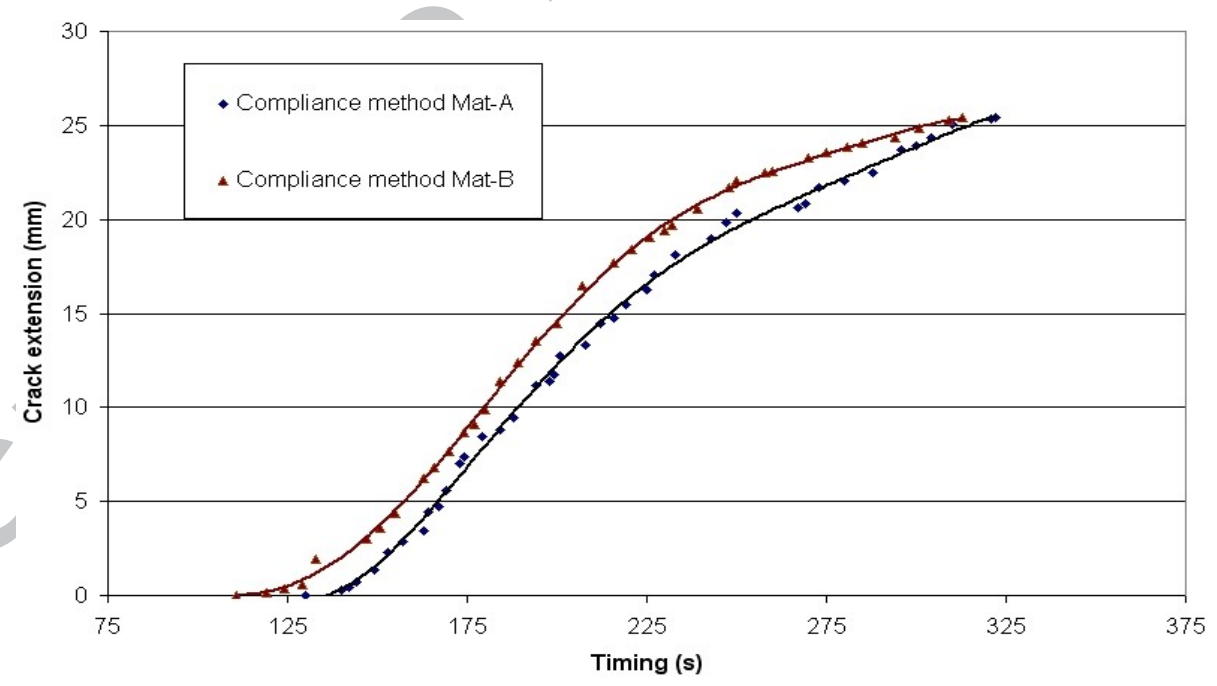

Fig. 10. Comparison of evolution of crack in two notch directions using crack extension vs timing 


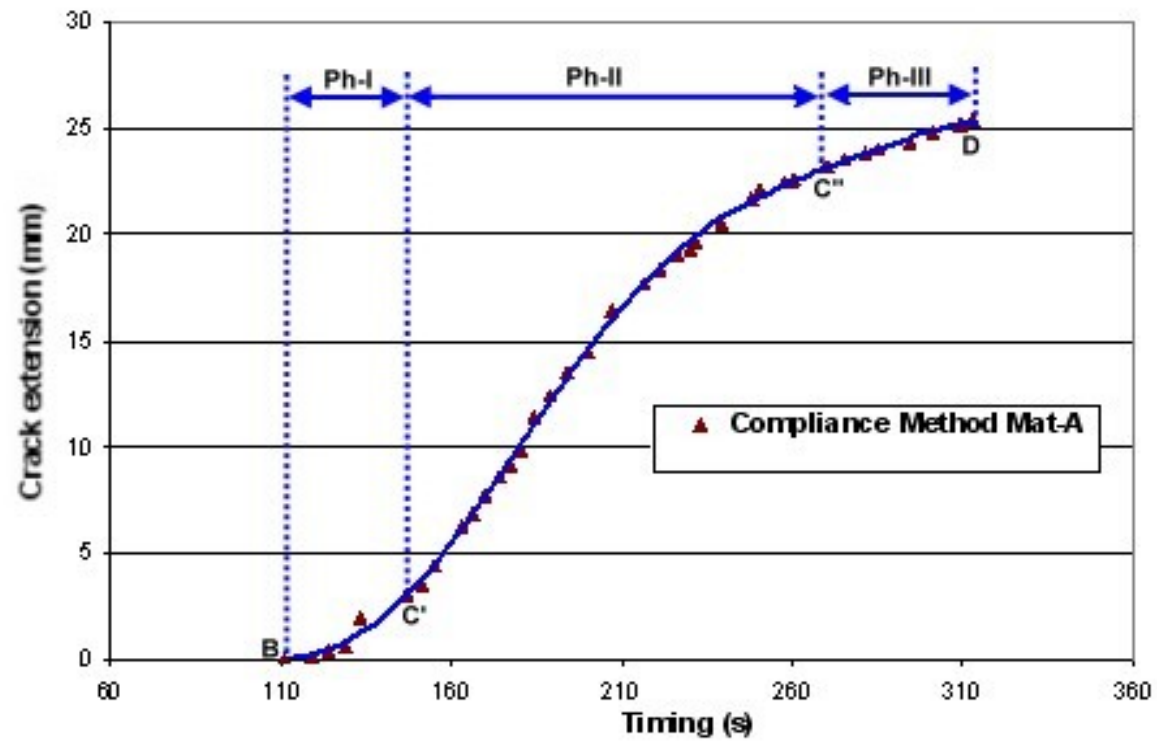

Fig. 11. Sequences of crack extension in composite reinforced woven fabric
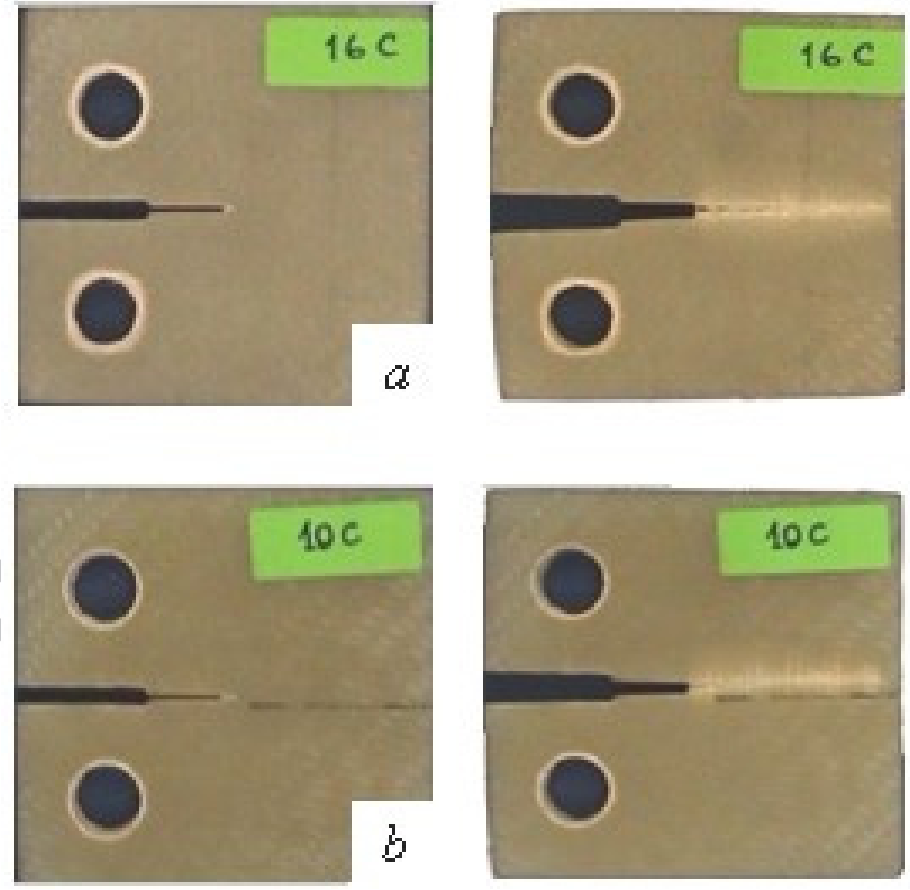

Fig. 12. Fracture path observed in a CT specimen

a) Mat-A

b) Mat- B 

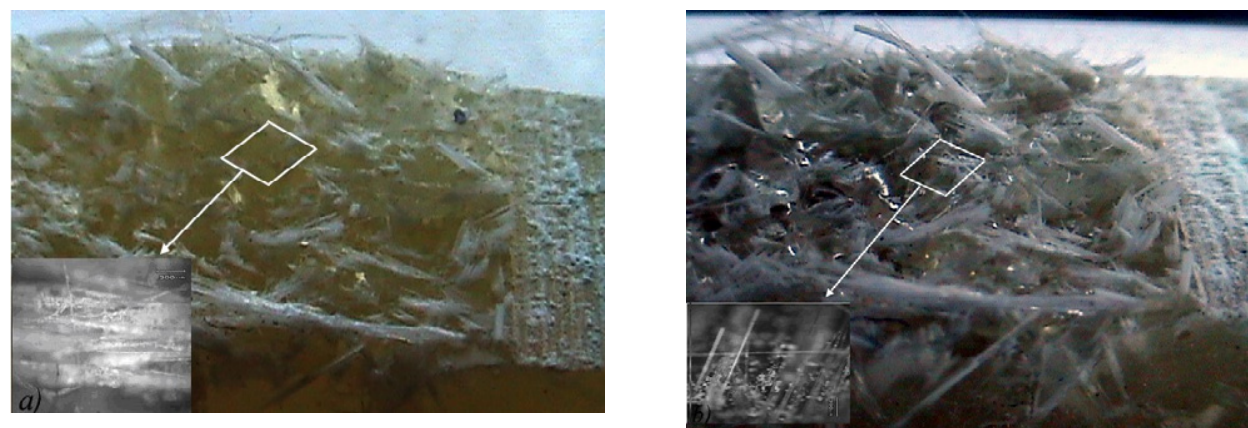

Fig. 13. The top surface view of CT specimens after fracture process a) Mat-A b) MatB

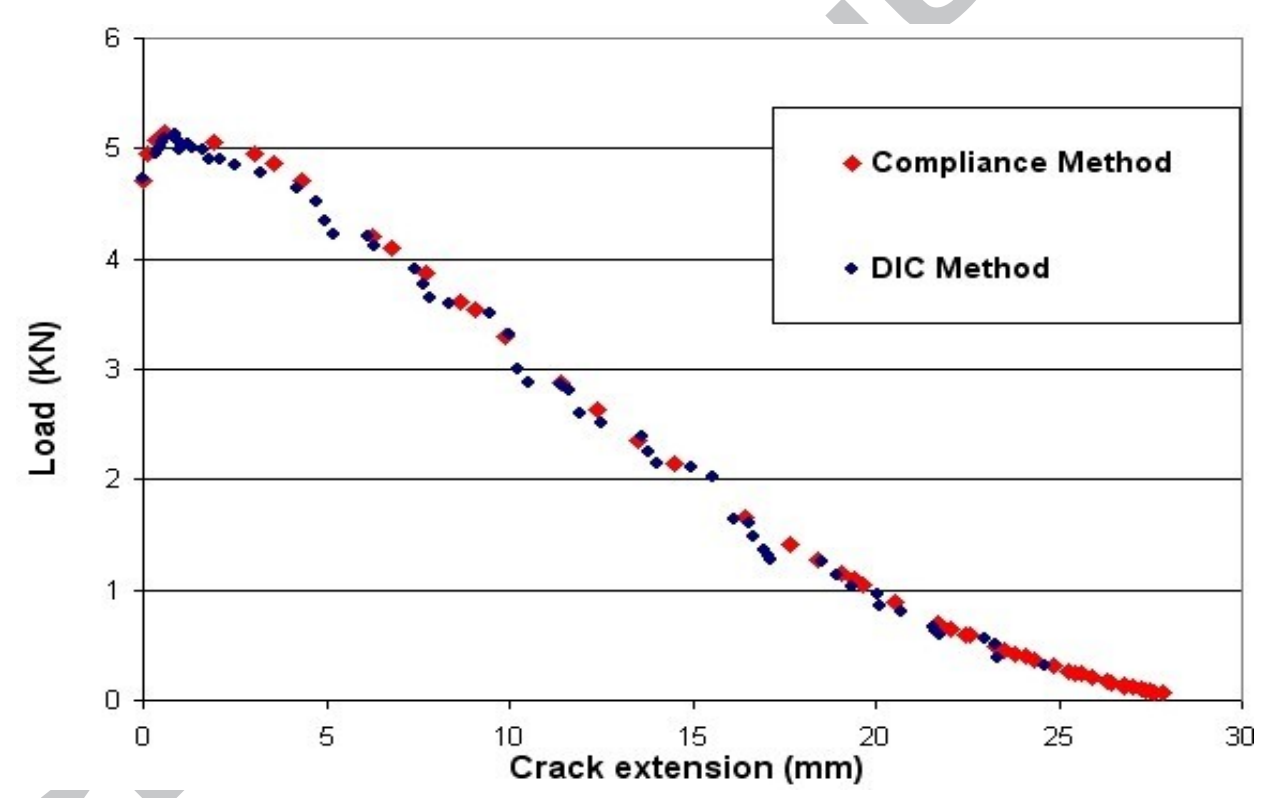

Fig. 14. Load vs crack growth curves for Mat-A using DIC and compliance method 


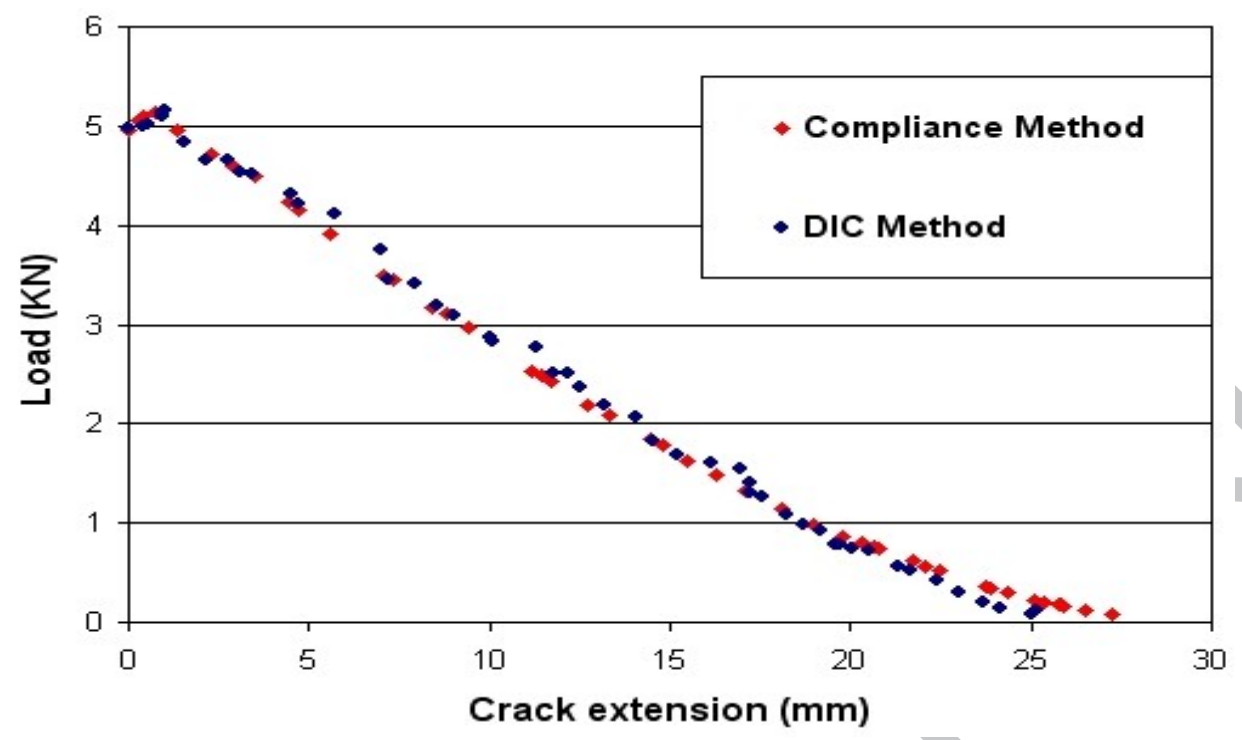

Fig. 15. Load vs crack growth curves for Mat-B using DIC and compliance method 

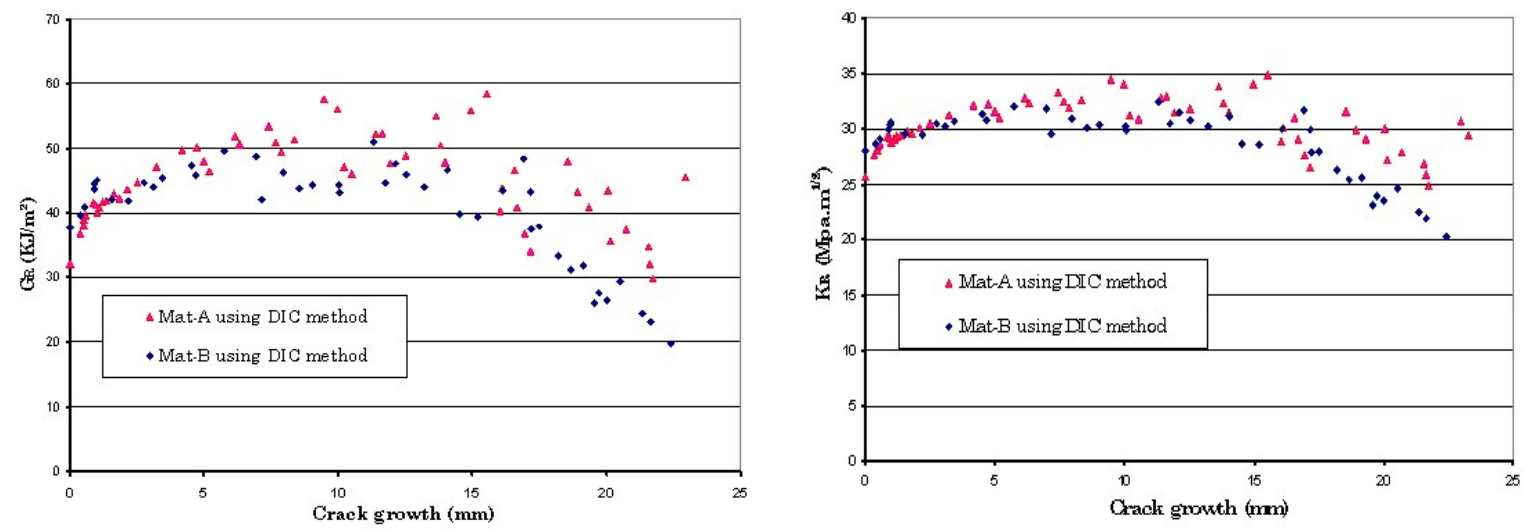

Fig. 16. Fracture toughness curves for Mat-A and Mat-B using DIC method
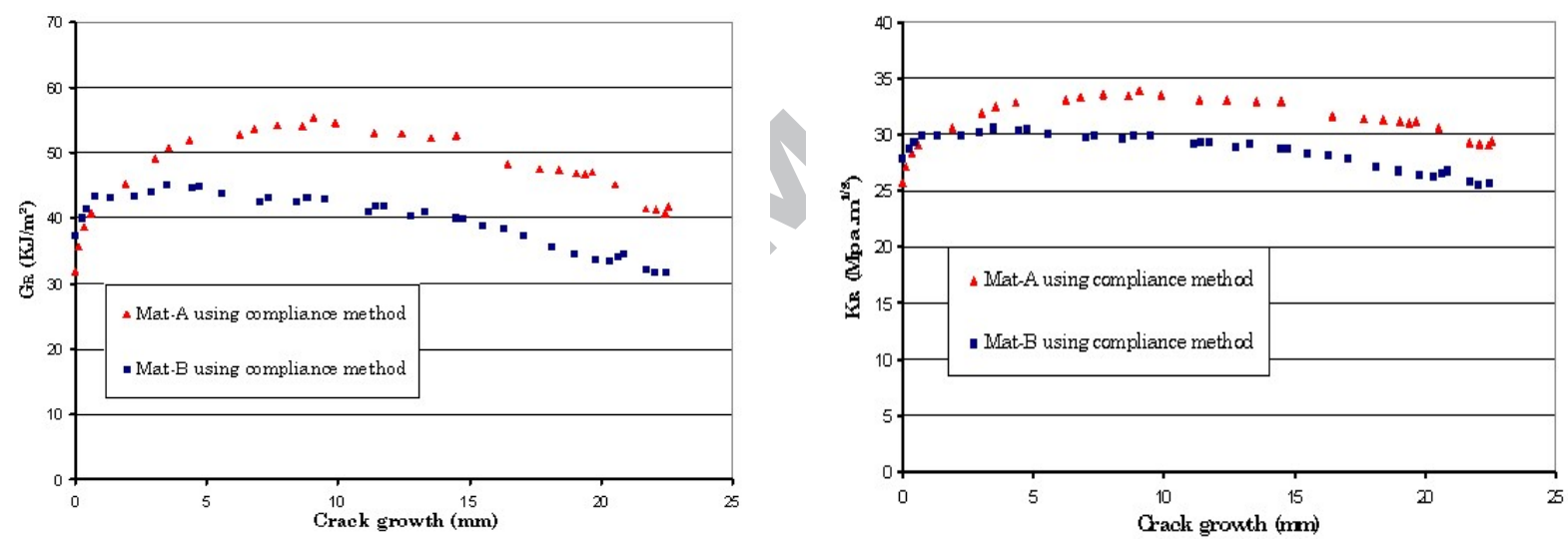

Fig. 17. Fracture toughness curves for Mat-A and Mat-B using compliance method 

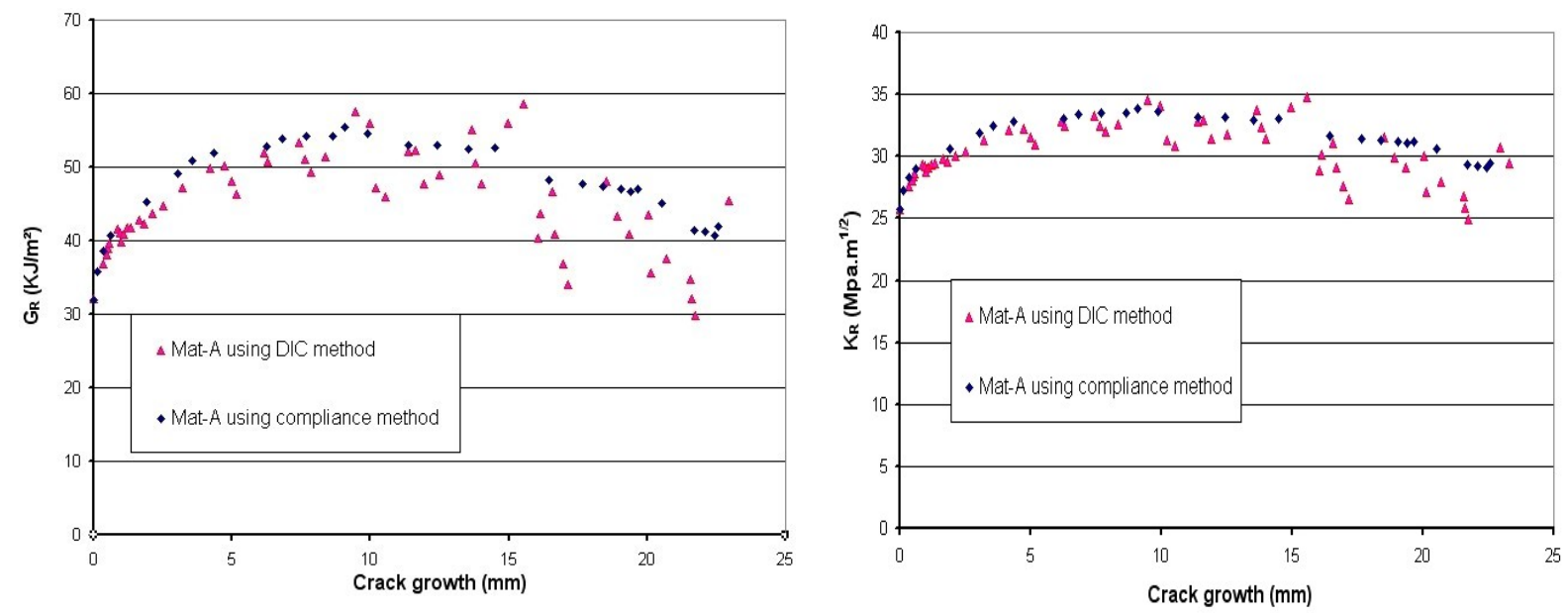

Fig. 18. Comparison of fracture toughness of Mat-A using DIC and compliance methods
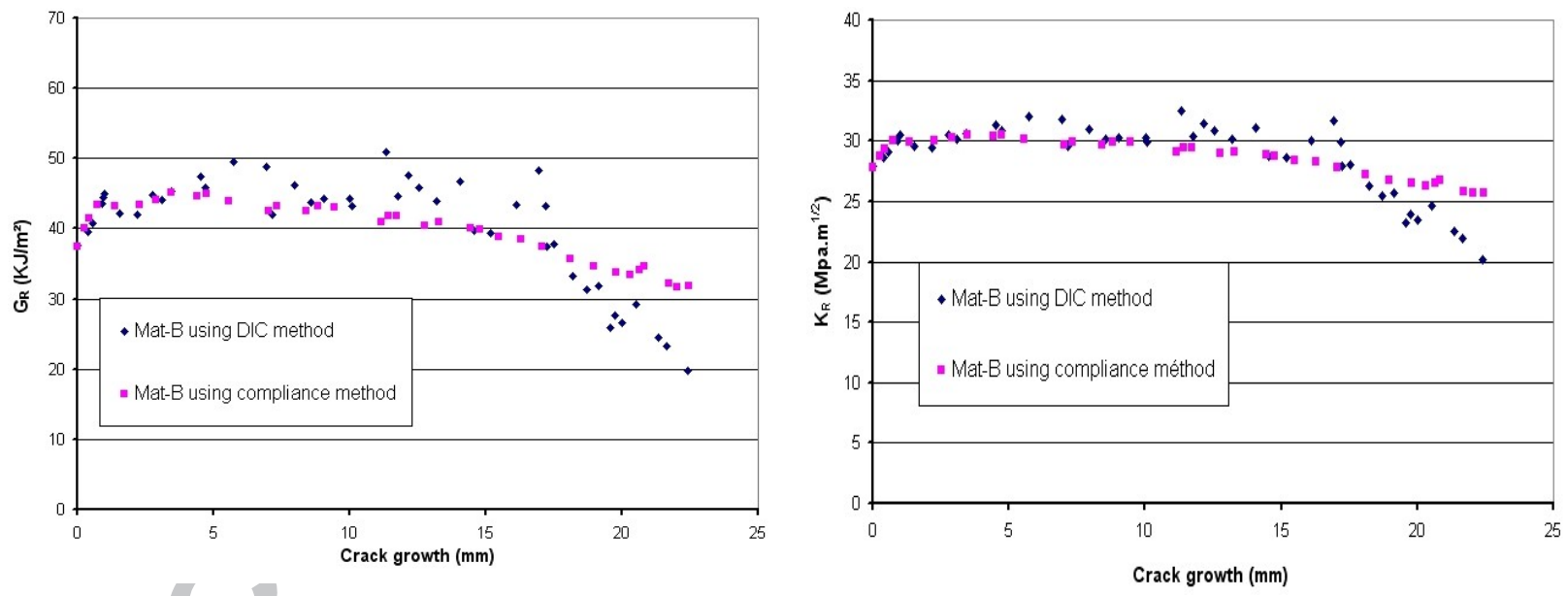

Fig. 19. Comparison of fracture toughness of Mat-B using DIC and compliance methods 


\section{ACCEPTED MANUSCRIPT}

\begin{tabular}{lcccc}
\cline { 2 - 5 } & \multicolumn{2}{c}{$\begin{array}{c}\mathrm{K}_{\mathrm{IC}} \\
\left(\mathrm{MPa}^{1 / 2}\right)\end{array}$} & \multicolumn{2}{c}{$\begin{array}{c}\mathrm{K}_{\mathrm{I}-\mathrm{Prop}} \\
\left(\mathrm{MPa} \cdot \mathrm{m}^{1 / 2}\right)\end{array}$} \\
\cline { 2 - 5 } & Compliance & DIC & Compliance & DIC \\
\hline Mat-A & 25.69 & 25.76 & $33.06-33.87$ & $30.86-34.54$ \\
\hline Mat-B & 27.84 & 27.93 & $29.13-30.51$ & $29.51-32.49$ \\
\hline
\end{tabular}

Table 4: Summary of fracture toughness results

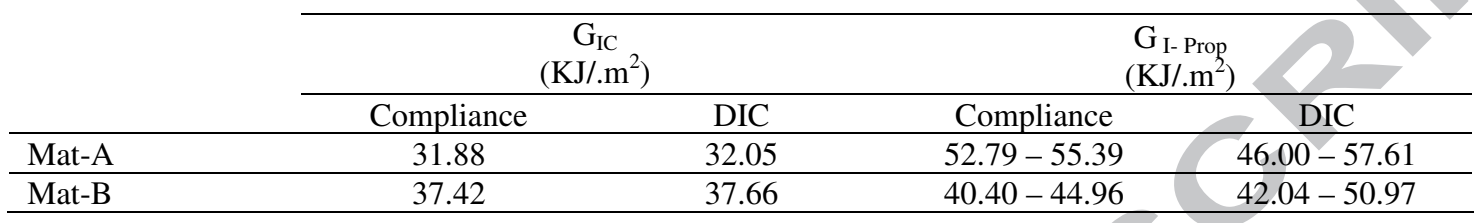

Table 5: Summary of energy release rate results 